e-ISSN: $1984-4255 \quad$ ARGUMENTOS

D01: $10.36517 /$ Argumentos.25.24

\title{
MAIA NETO, José Raimundo. $O$ ceticismo na obra de Machado de Assis. São Paulo: Annablume Editora, 2007, 198 p. ${ }^{1}$
}

\author{
Daniel Benevides Soares \\ https://orcid.org/0000-0001-7275-9217 - E-mail: benevides.soares@gmail.com
}

O ceticismo na obra de Machado de Assis é a tradução de uma obra originalmente publicada em inglês com o título "Machado de Assis, the Brazilian Pyrrhonian" em 1994 por José Raimundo Maia Neto. Esse estudo deriva da dissertação de mestrado defendida pelo autor em 1987 na PUC-RJ. Da primeira versão para a publicação em português, constituem modificação o título e passagens da introdução (MAIA NETO, 2007a, p. 224), como a atribuição do ensaio "Queda que as mulheres têm pelos tolos"2, de Victor Henaux, à autoria do próprio Machado (MAIA NETO, 2007a, p. 14.). Trata-se, segundo Gustavo Bernardo Krause (2005, p. 19), do melhor e mais abrangente trabalho a respeito do ceticismo na obra do Bruxo do Cosme Velho.

Maia Neto oferece como fio de Ariadne para a travessia da ficção machadiana a figura de um observador cético pirrônico que se constitui ao longo dos contos e dos romances da primeira e segunda fase atingindo sua forma mais bem acabada com o Conselheiro Aires, protagonista dos dois últimos romances, Esaú e Jacó e Memorial de Aires. É importante observar que o tipo de pirronismo em análise não é estritamente o pirronismo antigo, mas contempla também a tradição pirrônica moderna, já que Machado não teria tido contato pelo pirronismo pela via de Sexto Empírico, e sim pelas leituras de autores como Montaigne, Pascal, Voltaire, Plutarco e Luciano (MAIA NETO, 2007a, p. 20 e 2007b, p. 212). Isso não impede que os três momentos do ceticismo pirrônico - zetesis, epoche e ataraxia - perpassem de forma mais ou menos presente a obra machadiana desde a primeira fase constituindo gradativamente esse observador cético-pirrônico.

Para apresentar sua interpretação, Maia Neto elabora uma série de categorias especiais, localizadas ao longo da ficção machadiana, cujas principais são as seguintes. À vida social corresponde a vida exterior, lugar de opiniões precárias e contraditórias, de dualidade e hipocrisia. Já a paz doméstica pode ser entendida como o lugar de transparência, eticidade e verdade, oposto à

\footnotetext{
1 Agradeço ao professor José Raimundo Maia Neto pela gentileza da leitura.

${ }^{2}$ No original, De l'amour des femmes pour lês sots, originalmente publicado na França em meados do século XIX. Conferir a esse respeito (MAIA NETO, 2007a, p. 24-25).
} 
vida exterior e cuja representação consiste no casamento. Notamos que, segundo Maia Neto, no desenrolar da obra de Machado, especialmente dos romances da segunda fase, a vida exterior ocupa progressivamente o espaço da paz doméstica. Oscilando entre essas duas primeiras categorias, vida exterior e paz doméstica, a terceira apresenta o chamado homem de espírito como o personagem ético divorciado da vida exterior e que se opõe à conduta do tolo - quarta categoria que destacamos -, cujo traço essencial é a adoção de uma postura instrumental que, ao contrário do homem de espírito, cultiva uma disparidade entre a conduta exterior, representada pela aparência social, e os seus estados subjetivos (MAIA NETO, 2007a, p. 24; p. 38-39).

Mencionamos a 'conduta exterior' do tolo. Nesse ponto podemos aludir também a três diferentes perspectivas que os personagens tolos e homens de espírito adotam e cuja interação na vida exterior e na paz doméstica serve para a constituição do narrador cético pirrônico. $\mathrm{O}$ tolo - que na segunda fase machadiana passa a ser melhor designado como "medalhão" em referência ao conto Teoria do medalhão (MAIA NETO, 2007a, p. 45) - adota a chamada perspectiva estratégica, em que prevalece o uso de uma retórica composta de fórmulas socialmente estabelecidas, um entendimento da dimensão dramatúrgica da vida, segundo um conhecimento intuitivo da lógica que rege a vida social. O homem de espírito, por sua vez, apresenta uma perspectiva ingênua antes de ser vitimado pela crise cética que o conduzirá a adotar a perspectiva problemática. É importante mencionar que essas categorias, embora descrevam os protagonistas dos contos e romances machadianos, também se aplicam às personagens femininas, de modo que é possível observar a existência tanto de mulheres estratégicas - cuja expressão, se não a mais bem acabada, pelo menos a mais conhecida, é a indecifrável e inexaurível Capitu - quanto de espírito (MAIA NETO, 2007a, p. 42).

Na primeira fase da obra machadiana, o homem de espírito assume uma perspectiva ingênua que consiste na ausência de uma perspectiva reflexiva e na crença na paz doméstica como locus das essências em oposição às aparências reinantes na vida social. Ao longo do desenvolvimento da ficção machadiana, com o comprometimento cada vez maior da paz doméstica, a perspectiva ingênua cede lugar à perspectiva problemática. Esta se divide em dois tipos. O primeiro é aquele em que o personagem, após sofrer desilusões, encontra a paz doméstica; no segundo, por não alcançá-la, torna-se louco ou suicida (MAIA NETO, 2007a, p. 73-74). Progressivamente, o espaço para a paz doméstica é reduzido, comprometendo a perspectiva ingênua. A solução para que os personagens não adotem sempre a perspectiva problemática após a crise cética acarretada pela desventura da perspectiva ingênua é a substituição de uma postura interativa por uma contemplativa que desembocará em uma solução estético-cognitiva (MAIA NETO, 2007a, p. 40). Em Machado, portanto, aparece uma solução para essa crise na forma de uma fusão entre estetismo e pirronismo na figura do autor de memoriais, figura que se desenvolve nos narradores dos romances da segunda fase (MAIA NETO, 2007a, p. 23). De Brás Cubas até finalmente alcançar sua forma mais bem acabada em Aires, passando por Dom Casmurro, essa solução começa com um memorialista incapaz de praticar seu ceticismo em vida - o primeiro -, avança para um cujo pirronismo o exila da vida social - o segundo -, até culminar naquele que resolve a crise cética vivendo a ataraxia após consumar o manejo da solução estético-pirrônica - o Conselheiro Aires.

A relação de Machado de Assis com a filosofia já fora objeto da atenção, seja essa relação concebida como mais ${ }^{3}$ ou menos ${ }^{4}$ próxima. O ceticismo na obra de Machado de Assis oferece

\footnotetext{
${ }^{3}$ Conferir os estudos de: Paulo Margutti em História da filosofia do Brasil: o período colonial (1500-1822), p. 12; Benedito Nunes em Machado de Assis e a Filosofia, p. 7-23; Rosa Maria Dias em 'O autor de si mesmo': Machado de Assis Leitor de Schopenhauer, p. 382392; Élide Valarine Oliver em Humanitismo em Machado. Entre Spinoza, Voltaire e Leopardi; Alex Lara Martins em Machado de Assis: o filósofo brasileiro. Também de Maia Neto: Machado de Assis: ceticismo e literatura, p. 11-24 e O desenvolvimento de uma visão de vida cética na ficção de Machado de Assis, p. 377-396 e O delito capitolino, (2013, p. 59-71).

${ }^{4}$ Conferir o estudo de Miguel Reale (1973), A filosofia na obra de Machado de Assis \& Antologia filosófica de Machado de Assis.
} 
uma hipótese interpretativa da ficção do Bruxo do Cosme Velho que perpassa a primeira e segunda fases de sua obra, incluindo não apenas os romances, mas também os seus contos e se destaca dentre as que já abordaram o ceticismo presente em Machado de Assis por considerar o elemento cético-pirrônico como fundamental. O livro gerou um debate filosófico em torno de si, incluindo uma interpretação alternativa sobre a presença e o impacto do elemento cético em Machado oferecida por Paulo Margutti, destacando o seu pessimismo, feita a partir da leitura e discussão do livro de Maia Neto ${ }^{5}$. Se a concepção de pirronismo presente na obra de Machado conforme nos apresenta Maia Neto não se restringe ao pirronismo clássico, bebendo também de fonte pascaliana (MAIA NETO, 2016, p. 278), ambas se assemelham pelo caráter não sistemático, posto que o pirronismo pode ser definido como uma habilidade ou atitude mental e não como sistema filosófico entendido como um corpo articulado de doutrinas (MAIA NETO, 2007a, p. 14). Coerente com esse princípio, O ceticismo na obra de Machado de Assis contribui para ampliar os horizontes da legítima discussão filosófica, enfocando a ficção machadiana não apenas de forma ilustrativa. Desse modo, o livro de Maia Neto é referência fundamental e incontornável para a investigação dessa relação. Importante também por demonstrar que a resposta para a questão "o que é filosofia?" não cabe, sem mutilações, na solução única do que convencionalmente se concebe como sistema. Afinal, até onde se sabe, ninguém recebeu em pergaminho a procuração de Minerva.

\section{Referências}

BERNARDO, G. Quem me dera: o ceticismo de Machado de Assis. Sképsis, v. 1, n. 2, 2007. p. 171-183.

DIAS, R. M. "O autor de si mesmo": Machado de Assis leitor de Schopenhauer. Kriterion, Belo Horizonte, n. 112, dez. 2005. p. 382-392.

KRAUSE, G. B. O ceticismo não é um pessimismo, ou: a filosofia de Machado de Assis. Revista Interagir: pensando a extensão. Rio de Janeiro, n. 8, ago./dez. 2005. p. 19-26.

OLIVER, E. V. Humanitismo em Machado. Entre Spinoza, Voltaire e Leopardi. Machado de Assis em linha. São Paulo, v. 9, n. 18, ago. 2016. p. 09-27.

MAIA NETO, J. R. O desenvolvimento de uma visão cética na ficção de Machado de Assis. In: . Machado de Assis: lido e relido. São Paulo: Editora UNICAMP, 2016.

MAIA NETO, J. R. O delito capitolino. Aletria, v. 23, n. 1, jun./abr. 2013. p. 59-71.

MAIA NETO, J. R. O ceticismo na obra de Machado de Assis. São Paulo: Annablume, 2007a.

MAIA NETO, J. R. Machado, um cético brasileiro: resposta a Paulo Margutti e a Gustavo Bernardo. Sképsis, v. 1, n. 2, 2007b. p. 212-226.

MAIA NETO, J. R. Machado de Assis: ceticismo e literatura. In: . BERNARDO, G. Literaturae ceticismo. São Paulo: Annablume, 2005.

MARGUTTI, P. R. História da filosofia do Brasil: o período colonial (1500 - 1822). São Paulo: Edições Loyola, 2013.

\footnotetext{
${ }^{5}$ Conferir o artigo Machado, o brasileiro pirrônico? Um debate com Maia Neto (2007, p. 183-212). Integram também o debate em torno do livro os artigos Quem me dera: o ceticismo de Machado de Assis, de Gustavo Bernardo (2007, p. 171-183) e a resposta de Maia Neto aos dois artigos, Machado, um cético brasileiro: uma resposta a Paulo Margutti e a Gustavo Bernardo (2007b, p. 212-226).
} 
MARGUTTI, P. R. Machado, o brasileiro pirrônico? Um debate com Maia Neto. Sképsis, v. 1, n. 2, 2007. p. 183-212.

MARTINS, A. L. Machado de Assis: o filósofo brasileiro. Porto Alegre: Editora Fi, 2017.

NUNES, B. Machado de Assis e a filosofia. Revista Travessia. Santa Catarina, n. 19, 1989. p. 7-23.

REALE, M. A filosofia na obra de Machado de Assis \& Antologia. São Paulo: Livraria Pioneira Editora, 1973.

\section{Sobre o autor}

\section{Daniel Benevides Soares}

Professor da Faculdade Católica de Fortaleza (FCF). Doutor em Filosofia pela Universidade Federal do Ceará (UFC).

Recebido em: 12/07/2020.

Aprovado em: 12/10/2020.
Received:12/07/2020.

Approved: 12/10/2020. 